\title{
Demographic, socio-economic, and cultural factors affecting fertility differentials in Nepal
}

\author{
Ramesh Adhikari1,2
}

\begin{abstract}
Background: Traditionally Nepalese society favors high fertility. Children are a symbol of well-being both socially and economically. Although fertility has been decreasing in Nepal since 1981, it is still high compared to many other developing countries. This paper is an attempt to examine the demographic, socio-economic, and cultural factors for fertility differentials in Nepal.

Methods: This paper has used data from the Nepal Demographic and Health Survey (NDHS 2006). The analysis is confined to ever married women of reproductive age $(8,644)$. Both bivariate and multivariate analyses have been performed to describe the fertility differentials. The bivariate analysis (one-way ANOVA) was applied to examine the association between children ever born and women's demographic, socio-economic, and cultural characteristics. Besides bivariate analysis, the net effect of each independent variable on the dependent variable after controlling for the effect of other predictors has also been measured through multivariate analysis (multiple linear regressions).

Results: The mean numbers of children ever born (CEB) among married Nepali women of reproductive age and among women aged 40-49 were three and five children, respectively. There are considerable differentials in the average number of children ever born according to women's demographic, socio-economic, and cultural settings. Regression analysis revealed that age at first marriage, perceived ideal number of children, place of residence, literacy status, religion, mass media exposure, use of family planning methods, household headship, and experience of child death were the most important variables that explained the variance in fertility. Women who considered a higher number of children as ideal $(\beta=0.03 ; p<0.001)$, those who resided in rural areas $(\beta=0.02 ; p<0.05)$, Muslim women ( $\beta$ $=0.07 ; p<0.001)$, those who had ever used family planning methods $(\beta=0.08 ; p<0.001)$, and those who had a childdeath experience $(\beta=0.31 ; p<0.001)$ were more likely to have a higher number of CEB compared to their counterparts. On the other hand, those who married at a later age $(\beta=-0.15 ; p<0.001)$, were literate $(\beta=-0.05 ; p<$ 0.001 ), were exposed to both (radio/TV) mass media $(\beta=-0.05 ; p<0.001$ ), were richest $(\beta=-0.12 ; p<0.001$ ), and were from female-headed households $(\beta=-0.02 ; p<0.05$ ) had a lower number of children ever born than their counterparts.

Conclusion: The average number of children ever born is high among women in Nepal. There are many contributing factors for the high fertility, among which are age at first marriage, perceived ideal number of children, literacy status, mass media exposure, wealth status, and child-death experience by mothers. All of these were strong predictors for CEB. It can be concluded that programs should aim to reduce fertility rates by focusing on these identified factors so that fertility as well as infant and maternal mortality and morbidity will be decreased and the overall well-being of the family maintained and enhanced.
\end{abstract}

\section{Background}

Traditionally, Nepalese society has favored high fertility. Children are considered a symbol of both social and eco-

* Correspondence: rameshipsr@gmail.com

1 Geography and Population Department, Mahendra Ratna Campus, Tribhuvan University, Kathmandu, Nepal

Full list of author information is available at the end of the article nomic well-being. This is evident from a popular saying that says, "May your progeny fill the hills and mountains." Marriage is early and universal, and it is a viewed as a disgrace for a couple, particularly for the wife, not to have children. High fertility is desired because by producing children, preferably sons, a woman raises her status in the family [1]. Other reasons for high fertility include early 
and universal marriage as well as desire for sons, for both religious (to perform religious rituals) and economic (immediate economic gains and old age security) reasons [2].

The total fertility (TFR) rate has decreased worldwide [3] just as it has in Nepal, where fertility has declined significantly from 6.3 births per women [4] in 1981 to 3.1 births per women in 2009 [3]. The Nepali government began setting fertility reduction targets as early as 1965 , but they were never met. During the Third Plan (196570) period, the target was to reduce the estimated crude birth rate (CBR) of 39.1 in 1967 to 38.1 in 1971. During the Fifth Plan (1975-80) period, the newly estimated CBR of 40 was to be reduced to 38 by 1980 [5]. Similarly, the Seventh Plan (1985-90) planned to achieve a TFR of about four children per woman by the end of the plan period [6]. But the demographic information shows that Nepal's TFR was above five until the early1990s [7] and above four even in 2001 [8].

The status of Nepal in many of the major demographic and other indicators is very poor $[3,9,10]$. However, the TFR decreased about 25 percent (4.1 births per women in 2001 to 3.1 births per women in 2006) between the two surveys $[8,10]$. In particular, the education of women, female labor force participation, urban residence, household wealth, cultural norms, and overall levels of social development have affected fertility [11-14]. Besides these phenomena, many other factors, such as the internal as well as external displacement of people due to the decade-long political insurgency (1995-2006), may also be fundamental reasons for this change in fertility in Nepal. In addition, there has been a tremendous outflow of migrants seeking work in foreign countries, especially in Persian Gulf and Southeast Asian countries. Furthermore, exposure to modern means of communications, increase in family planning awareness, and easy access to modern family planning may also lower the TFR [10].

Fertility is one of the three principal components of population dynamics that determine the size and structure of the population of a country [15]. Differentials in fertility behavior and fertility levels in different areas and among population strata or characteristics have been among the most pervasive findings in demography [16]. Although Nepal has seen substantial improvements in its reproductive health outcomes, such as in the reduction in maternal and infant mortality, the increase in the contraceptive prevalence rate, and health service utilization among married women $[10,17]$, the total fertility rate is still high compared to that of other developing countries [3]. The underlying cause of high fertility in Nepal needs further investigation and exploration in order to be better understood and appropriately addressed by reproductive health programs. It is essential to identify the risk factors associated with high fertility and to provide services to address those who are at risk. To develop effective strategies for fertility control, it is necessary to understand the factors affecting fertility. It is hypothesized that women in vulnerable groups, such as those who got married at an early age, are illiterate, are living in rural areas, are poorest, and have very little knowledge of contraceptives, have high fertility.

This paper is an attempt to examine the fertility differentials among Nepali women. More specifically, it aims to investigate whether demographic, socioeconomic and cultural factors have an impact on fertility in the Nepali context. This paper also aims to guide reproductive health program planners and policymakers to understand various factors influencing fertility in order to assist in the implementation of a reproductive health program that will decrease fertility as well as infant and child morbidity and mortality.

\section{Methods}

\section{Sources of data}

This paper uses data from the Nepal Demographic and Health Survey (NDHS), 2006, consisting of nationally representative sample surveys. The primary purpose of this survey was to furnish policymakers and planners with detailed information on fertility, family planning, infant, child, adult, and maternal mortality, maternal and child health, nutrition, and knowledge of HIV/AIDS and other sexually transmitted infections. The 2006 NDHS was carried out under the aegis of the Population Division of the Ministry of Health and Population. The data used in this study is publicly available.

\section{Sampling frame and sampling selection}

The 2006 NDHS used the sampling frame provided by the list of census enumeration areas with population and household information from the 2001 Population Census. Each of the 75 districts in Nepal is subdivided into Village Development Committees (VDCs), and each VDC into wards. The primary sampling unit (PSU) for the 2006 NDHS is a ward, sub-ward, or group of wards in rural areas, and sub-wards in urban areas. The sample for the survey is based on a two-stage, stratified, nationally representative sample of households. At the first stage of sampling, 260 PSUs (82 in urban areas and 178 in rural areas) were selected using systematic sampling with probability proportional to size. At the second stage of sampling, systematic samples of about 30 households per PSU on average in urban areas and about 36 households per PSU on average in rural areas were selected in all the regions. Interviews were completed for 10,793 women of reproductive age.

\section{Dependent and independent variables}

This paper analyzed the specific measure of fertility; i.e. children ever born (CEB). So the dependent variable used 
in this paper is CEB. CEB comprises information on the number of all children born alive (lifetime fertility) up to the survey date. Mean number of children ever born to women represents the childbearing experience of a real age cohort and reflects current and past fertility behavior. Finally, CEB does allow for the generalization of data and an understanding that can provide the basis for further analysis [15].

Children ever born, the dependent variable, is treated as an interval scale in both bivariate and multivariate analyses. The children ever born to all women irrespective of the age group (lifetime fertility) and women aged 40-49 (completed fertility) were analyzed separately as a measure of fertility. The demographic, socioeconomic, and cultural variables used as independent variables are: age group of respondents, age at first marriage, place of residence, literacy status, occupation, religion, mass media exposure, wealth status, knowledge, and previous use of family planning methods, household headship, and child-death experience by mothers. Many of the independent variables were categorically variable. For example, the variable perceived ideal number of children refers to respondents' perceptions concerning the ideal number of children they would like to have. This variable is categorized into two categories (up to two children and three or more children) for bivariate analyses and is used as an interval scale for multivariate analysis. Similarly, the variable "religion" measures respondents' religious affiliation. Those respondents who are affiliated with Hindu religion are considered as Hindu, those affiliated with Islam are considered as Muslim, and the respondents affiliated with other religions are categorized as "other religion." Regarding knowledge about family planning methods, almost all respondents (99.5\%) had heard of at least one family planning (FP) method. So, the "knowledge of FP" variable is measured by scoring the knowledge of each method. This variable is classified into two categories. The average number of methods heard was taken as a guide for making these two categories. Scores higher than average (average score $=7.1$ ) were classified as "higher" and scores lower than average were classified as "lower" level of knowledge.

Radio and TV are considered as routes of access to health information in this study. A composite index was made from these variables. Then the variable was categorized into three categories. If the respondent was not exposed to any media, the classification was treated as "no exposure." The other categories were "exposed to one media (either radio or TV)" and "exposed to both media (radio and TV)." The categories of the other independent variables were also created in the same way, based on the literature as well as their frequency distribution.

\section{Methods of analysis}

The analysis is confined to women who were ever married $(\mathrm{N}=8644)$. Data were weighted to represent the structure of Nepali population using weighting factors provided with the NDHS. Initially, univariate or descriptive analysis was used to describe the percentage and number of respondents according to sociodemographic characteristics. Both bivariate and multivariate analyses were performed to show the fertility differentials. The dependent variable (CEB) is in continuous scale. We analyzed the mean number of children ever born and other independent variables using one-way ANOVA to examine the association between children ever born and women's demographic, socioeconomic, and cultural characteristics. Furthermore, the net effect of each predictor variable on the dependent variable after controlling for the effect of other predictors was also measured via multivariate analysis (multiple linear regressions). Analysis was performed separately for all women and for women aged 40-49 in both bivariate and multivariate analyses. Before using multiple linear regressions, the correlation matrix has been applied to discover the degree and direction of the relationship between each pair of independent variable and dependent variable. The results demonstrated that there was no multi-colinearity $(r>0.6)$ between each pair of independent variables and dependent variable. So all the variables included in the bivariate analysis were also included in multivariate linear regression. The Statistical Package for Social Science (SPSS 11.5 for window) software was used to analyze the data.

\section{Results}

\section{Background characteristics of women}

More than a quarter of the ever married women (28\%) were youth aged 15-24 and slightly more than a fifth (23\%) were aged 40-49. A considerable proportion of the women (33\%) were married before the age of 16 . A majority of the women lived in rural areas (85\%), and most women were illiterate (63\%). Similarly, only about one out of ten women $(12 \%)$ were engaged in non-agricultural sectors. An overwhelmingly large majority of the women were Hindu (86\%). Likewise, a large percentage of women had been exposed to at least one mass medium (radio or TV). Furthermore, almost two-fifths of the women (39\%) fell into the poor or the poorest category. On average, women were aware of 7.1 family planning methods. A majority of the women (58\%) had little knowledge (less than average) of family planning methods. It is notable that more than a third of women (34\%) had never used any family planning methods. Furthermore, only about a fifth $(21 \%)$ were from female-headed households. Sur- 
prisingly, more than a quarter of the women (28\%) had experienced child-death (Table 1).

\section{Demographic, socio-economic, and cultural correlates of children ever born}

The mean numbers of children ever born among married Nepali women of reproductive age (15-49) and among the married women aged 40-49 were three children and five children, respectively. Several demographic, socioeconomic and cultural variables were correlated with children ever born. The mean numbers of children ever born to women whose age at marriage was less than 16 years, who perceived a higher number of children as ideal, and who resided in mountain areas were significantly higher than their counterparts.

Regarding literacy status, literate women have only half the CEB than do illiterate women (1.9 vs. 3.7 for all; 3.6 vs. 5.2 for women aged 40-49). Furthermore, Muslim women, women who had never been exposed to mass media, and poor/poorest women had significantly higher CEB than their comparison group. Similarly, those women who had less knowledge about family planning methods had significantly more CEB than those who had a higher level of knowledge about FP. In contrast, women who had used family planning methods before had more CEB than those who had never used them. Notably, women who had a child-death experience had almost double the number of CEB than those who did not have such an experience. Furthermore, the mean CEB is significantly higher among women aged 40-49 in male-headed households compared to women in female-headed households (5.0 vs. 4.7) (Table 2).

\section{Multivariate analysis}

Two separate multivariate analyses (one for all women and one for women aged 40-49) were performed. When all these independent variables and the number of children ever born were included in the logistic model, Rsquare was 0.59 for the all women category and 0.33 for the women aged 40-49 category. This means that the variables included in the models can explain the variation in the number of children ever born of all women by 59 percent $(\mathrm{p}<0.001)$ and 33 percent $(\mathrm{p}<0.001)$ among the women aged $40-49$ years (Table 3 ).

The multivariate analysis found that women's age, age at marriage, perceived ideal number of children, place of residence, literacy status, religion, mass media exposure, wealth status, ever use of FP methods, household headship, and child-death experience by mothers to be significant predicators of fertility in both groups (all women and women aged 40-49). The coefficients shown in Table 3 represent the effect of each independent variable on the dependent variable. Results show that a low age at first marriage significantly and negatively affected the number of children ever born at 0.001 significant levels. To be more precise, increase in women's age at first marriage tended to decrease the number of children ever born, while other variables in the model were controlled $(\beta=-$ 0.15 for all women; -0.13 for women aged 40-49). Similarly, the coefficient ( $\beta=0.026$ for all women; 0.038 for women aged 40-49) of perceived ideal number of children showed a significant $(\mathrm{p}<0.001)$ positive effect on fertility. Women who ideally considered it better to have more children were indeed likely to a have higher number of children ever born than those who perceived a low number of children as ideal.

Regarding literacy status, literate women tended to have fewer children than illiterate women $(\mathrm{p}<0.001)$. The study also found out that a woman's religion was an important factor in her fertility. For example, Muslim women were likely to have more children $(\beta=0.066$ for all women; $\beta=0.146$ for women aged 40-49) than Hindu women. On the other hand, Buddhist and Christian women were likely to have fewer children than did Hindu women. Furthermore, those women who are exposed to both mass media (radio and TV) were likely ( $\beta=-0.049$ for all women; -1.96 for women aged 40-49) to have fewer children than those who were not exposed to any media (Table 3).

Our analysis showed that the rich/richest women were likely to have fewer children $(\beta=-0.12$ for all women and -0.15 for women aged 40-49) than those who were poorest. Furthermore, our study showed that household headship also affects fertility. Ever married women from female-headed households were likely to have fewer children than did women from male-headed households ( $\beta=$ -0.016 for all women; -0.038 for women aged $40-49$ ). It is notable that women who had a child-death experience were more likely to have more children than women who did not experience child death ( $\beta=0.31$ for all women; $\beta$ $=0.39$ for women aged 40-49) (Table 3 ).

\section{Discussion}

The study found that on average married Nepali women of reproductive age woman give birth three times and women aged 40-49 five times. This high number of children ever born indicates that more family planning and reproductive health programs are needed. All women, regardless of demographic, socioeconomic or cultural status, would benefit if programs focus on reducing fertility.

Considerable differences in CEB according to women's age, age at marriage, perceived ideal number of children, place of residence, literacy status, religion, mass media exposure, wealth status, ever use of FP methods, household headship, and child-death experience by mothers were found in the study. As in other studies, our study also found that older women have a significantly higher 
Table 1: Demographic, socioeconomic, and cultural characteristics of women.

\begin{tabular}{|c|c|c|c|}
\hline Characteristics & & Percent & Number \\
\hline \multirow[t]{3}{*}{ Age group } & $15-24$ & 28.0 & 2424 \\
\hline & $25-39$ & 48.7 & 4213 \\
\hline & $40-49$ & 23.2 & 2007 \\
\hline \multirow[t]{2}{*}{ Age at fist marriage } & Less than $16 \mathrm{yrs}$ & 32.6 & 2814 \\
\hline & 16 or more yrs & 67.4 & 5827 \\
\hline \multirow[t]{2}{*}{ Perceived ideal Number of children } & Up to 2 children & 32.6 & 2814 \\
\hline & 3 or more children & 67.4 & 5827 \\
\hline \multirow[t]{2}{*}{ Place of residence } & Urban & 14.8 & 1280 \\
\hline & Rural & 85.2 & 7363 \\
\hline \multirow[t]{3}{*}{ Ecological Zones } & Mountain & 7.1 & 611 \\
\hline & Hill & 41.4 & 3576 \\
\hline & Terai & 51.6 & 4457 \\
\hline \multirow[t]{2}{*}{ Literacy status } & Illiterate & 62.6 & 5409 \\
\hline & Literate & 37.4 & 3234 \\
\hline \multirow[t]{3}{*}{ Occupation } & Not working & 16.3 & 1411 \\
\hline & Agricultural sector & 71.9 & 6213 \\
\hline & Non-agricultural sector & 11.8 & 1020 \\
\hline \multirow[t]{3}{*}{ Religion } & Hindu & 85.5 & 7392 \\
\hline & Muslim & 4.0 & 347 \\
\hline & Other & 10.5 & 905 \\
\hline \multirow[t]{3}{*}{ Mass media exposure } & No exposure & 8.6 & 742 \\
\hline & One media (radio or TV) exposure & 26.0 & 2251 \\
\hline & Both (radio \& TV) exposure & 65.4 & 5651 \\
\hline \multirow[t]{3}{*}{ Wealth Status } & Poor/poorest & 38.6 & 3338 \\
\hline & Middle & 21.1 & 1827 \\
\hline & Rich/Richest & 40.2 & 3479 \\
\hline \multirow[t]{2}{*}{ Knowledge about FP } & Lower & 57.7 & 4990 \\
\hline & Higher & 42.3 & 3653 \\
\hline \multirow[t]{2}{*}{ Ever used of FP methods } & Never used & 33.5 & 2898 \\
\hline & Ever used & 66.5 & 5746 \\
\hline \multirow[t]{2}{*}{ Child death experience+ } & No & 72.2 & 5634 \\
\hline & Yes & 27.8 & 2175 \\
\hline
\end{tabular}


Table 1: Demographic, socioeconomic, and cultural characteristics of women. (Continued)

\begin{tabular}{llll}
\hline Household headship & Male headed & 79.2 & 6845 \\
& Female headed & 20.8 & 1799 \\
\hline & Total & $\mathbf{1 0 0 . 0}$ & $\mathbf{8 6 4 4}$ \\
\hline
\end{tabular}

Note + information of child death experienced were collected from women who have ever given birth $(n=7809)$

number of CEB. It could be that the expected number of children will increase as women's age increases [18]. Similarly, as we hypothesized, those women who married early were likely to a have higher number of children than their counterparts. An increase in the age at first marriage has an adverse effect on high fertility. Early marriage not only marks a woman's entry into a sexual union and the beginning of exposure to childbearing but may also be an important gauge of women's status, since the older the woman is when she marries, the greater the likelihood that she has attended school or been employed, and the greater her chances of having a more equal relationship with her husband [19]. Our finding is similar to many other studies that find that older age at first marriage played an important role in reduction in fertility [20-23]. Furthermore, our study found that women who perceived more children as ideal were likely to have more children ever born than those who perceived a low number of children as ideal. It could be that the ideal number of children is one of the most important predictors in determining women's desire to stop childbearing and one that affects women in terms of their accepting contraceptives and fertility planning [24].

The present study also shows that rural women have higher fertility than urban women. Our study result is similar to many other studies [25-28]. One reason could be that urban women are more likely to use contraceptives than are rural women; therefore, the fertility levels in urban and rural areas tend to be different $[29,30]$. The other reason could be that people who live in rural areas tend to marry at a younger age than do those in urban areas [31]. Similarly, the higher CEB among women in mountain areas could be because mountain areas are sparsely populated and also less developed overall than other ecological regions. Mountain regions are also remote and inaccessible compared to most Terai (the southern plains) and hill settlements, which are accessible by road. Socioeconomically too, the Terai region is better off. The other reason could be that more than half the urban population lives in the Terai [1].

It is well known that the fertility of a woman is negatively associated with her level of education [32]. We hypothesized that illiterate women are more likely to have a higher number of children than are literate women. This study also showed that illiterate women have almost double the number of CEB than do literate women. Education exposes women to information, empowers women, makes them more likely to be employed outside their home environment, and makes them more aware of their own health and the health of their children-all of which are negatively associated with the number of children a woman will have during her reproductive life. Similarly, educated women are more likely to postpone marriage, have smaller family size, and use contraception than are uneducated women [33]. Other studies also suggest that education has a negative effect on women's cumulative fertility [34-36].

This study found that Muslim women were more likely to have more children than were to Hindu women. It could be that religion has an immense social, economic, and political significance in most societies, and thus plays an important role in sanctioning or promoting acceptance of or creating resistance to family planning [37-40]. Although both Islam and Hinduism are pronatalist religions, these religions differ in regard to their beliefs concerning marriage, reproductive behavior, and fertility control [41]. Our study finding is similar to that of many other studies [42-45].

Throughout the world, mass media have influenced knowledge, attitudes, and behavior regarding the use of contraception [46]. Our study also found that mass media exposure (radio/TV) has an important effect on reproductive behavior. Those women who were exposed to radio/TV had fewer children than those who were not exposed. It could be because radio and television programs and the values they disseminate are transmitted directly into the home, they have the potential to directly affect every member of the household, even those with little or no schooling $[47,48]$. The role of mass media in changing both patterns of contraceptive use and notions of ideal family size could be another reason for low fertility among those exposed to mass media [49].

We hypothesized that the poorest women would have higher fertility than the richest women. The relation of wealth and fertility can be clearly seen in the study. An inverse relationship was observed between wealth status and fertility, with significantly lower fertility among the richest women compared to fertility among the poorest. This result is the same as for other studies [50,51]. The reason could be that poor people may perceive children 
Table 2: Mean number of children ever born to ever married women aged 15-49 and women aged 40-49 by demographic, socioeconomic, and cultural characteristics.

\begin{tabular}{|c|c|c|c|c|c|c|c|}
\hline & & \multicolumn{3}{|c|}{ All women } & \multicolumn{3}{|c|}{ Women aged 40-49 } \\
\hline & & Mean CEB & SD & F-Value & Mean CEB & SD & F-Value \\
\hline \multirow[t]{3}{*}{ Age group } & $15-24$ & 1.15 & 1.0 & $2797.9^{* * *}$ & - & - & - \\
\hline & $25-39$ & 3.22 & 1.7 & & - & - & - \\
\hline & $40-49$ & 4.96 & 2.3 & & 4.96 & 2.3 & - \\
\hline \multirow[t]{2}{*}{ Age at first marriage } & Less than $16 \mathrm{yrs}$ & 3.6 & 2.3 & $304.1^{* * *}$ & 5.3 & 2.5 & $30.9^{* * *}$ \\
\hline & 16 or more yrs & 2.8 & 2.1 & & 4.7 & 2.2 & \\
\hline \multirow[t]{2}{*}{ Perceived ideal Number of children } & Up to 2 & 2.4 & 1.7 & $1744.3^{* * *}$ & 4.1 & 2.1 & $230.3^{* * *}$ \\
\hline & 3 or more & 4.2 & 2.3 & & 5.6 & 2.3 & \\
\hline \multirow[t]{2}{*}{ Place of residence } & Urban & 2.5 & 1.8 & $105.2^{* * *}$ & 3.8 & 2.0 & $79.7^{* * *}$ \\
\hline & Rural & 3.1 & 2.2 & & 5.1 & 2.3 & \\
\hline \multirow[t]{3}{*}{ Ecological Zones } & Mountain & 3.3 & 2.4 & & 5.5 & 2.6 & \\
\hline & Hill & 2.9 & 2.1 & $11.2^{* * *}$ & 4.7 & 2.3 & $9.2^{* * *}$ \\
\hline & Terai & 3.1 & 2.2 & & 5.1 & 2.3 & \\
\hline \multirow[t]{2}{*}{ Literacy status } & Illiterate & 3.7 & 2.3 & $1657.6^{* * *}$ & 5.2 & 2.3 & $99.5^{* * *}$ \\
\hline & Literate & 1.9 & 1.5 & & 3.6 & 1.7 & \\
\hline \multirow[t]{3}{*}{ Occupation } & Not working & 2.2 & 1.8 & & 4.2 & 2.1 & \\
\hline & Agricultural & 3.3 & 2.3 & $173.4^{* * *}$ & 5.1 & 2.3 & $25.2^{* * *}$ \\
\hline & Non-agricultural & 2.6 & 1.9 & & 4.4 & 2.4 & \\
\hline \multirow[t]{3}{*}{ Religion } & Hindu & 3.03 & 2.1 & & 4.89 & 2.3 & \\
\hline & Muslim & 3.52 & 2.7 & $8.9^{* * *}$ & 6.91 & 2.6 & $28.5^{* * *}$ \\
\hline & Other & 2.97 & 2.2 & & 4.83 & 2.4 & \\
\hline \multirow[t]{3}{*}{ Mass media exposure } & No exposure & 3.9 & 2.5 & & 5.7 & 2.4 & \\
\hline & One media (radio or TV) exposure & 3.5 & 2.3 & $168.9^{* * *}$ & 5.3 & 2.4 & $28.3^{* * *}$ \\
\hline & Both (radio \& TV) exposure & 2.7 & 2.0 & & 4.7 & 2.2 & \\
\hline \multirow[t]{3}{*}{ Wealth Status } & Poor/poorest & 3.5 & 2.4 & $134.2^{* * *}$ & 5.6 & 2.4 & $64.9^{* * *}$ \\
\hline & Middle & 3.1 & 2.1 & & 5.0 & 2.2 & \\
\hline & Rich/Richest & 2.6 & 1.8 & & 4.3 & 2.1 & \\
\hline \multirow[t]{2}{*}{ Knowledge about FP } & Lower & 3.3 & 2.3 & $168.5^{* * *}$ & 5.1 & 2.4 & $21.8^{* * *}$ \\
\hline & Higher & 2.7 & 1.9 & & 4.6 & 2.2 & \\
\hline \multirow[t]{2}{*}{ Ever used of FP methods } & Never used & 2.5 & 2.4 & $278.2^{* * *}$ & 4.7 & 2.7 & $12.2^{* * *}$ \\
\hline & Ever used & 3.3 & 2.0 & & 5.1 & 2.1 & \\
\hline
\end{tabular}


Table 2: Mean number of children ever born to ever married women aged 15-49 and women aged 40-49 by demographic, socioeconomic, and cultural characteristics. (Continued)

\begin{tabular}{|c|c|c|c|c|c|c|c|}
\hline \multirow[t]{2}{*}{ Experience of child death } & No & 2.7 & 1.5 & \multirow[t]{2}{*}{$3452.7^{* * * *}$} & 4.0 & 1.8 & \multirow[t]{2}{*}{$579.6^{* * *}$} \\
\hline & Yes & 5.2 & 2.1 & & 6.1 & 2.1 & \\
\hline \multirow[t]{2}{*}{ Household headship } & Male headed & 3.1 & 2.2 & 2.7 & 5.0 & 2.3 & $3.9^{*}$ \\
\hline & Female headed & 3.0 & 2.0 & & 4.7 & 2.3 & \\
\hline Total mean & & 3.0 & 2.2 & & 5.0 & 2.3 & \\
\hline Total N & & 8644 & & & 2007 & & \\
\hline
\end{tabular}

as a source of income, thus motivating them to have more children [2]. Another reason could be that the poorest people have less access to education and family planning methods.

In contrast to other research [52-54], our results indicate that those women who had ever used contraception had more children ever born than those who did not use contraception. It could be that women adopt contraception when they reach or exceed the target number of children they would like to have [55].

Another interesting finding of this study was that women from female-headed households had fewer children than women from male-headed households. During the recent period of conflict in Nepal, many people, especially males, have left their villages and have gone to other countries for employment. The low fertility among female-headed households could be due to the extended separation of women from their husbands. Furthermore, almost three out of four women (73\%) from femaleheaded households were themselves the head of their household. Most of these female household heads had high status in their family. Previous research has also shown that women's high social status is positively correlated with their health status [56,57]. A study in Sri Lanka found that women in households headed by females used health services more frequently than those in maleheaded households [58]. The possible explanation could be that women who have autonomy in decision making are more likely to have higher level of contraceptive use, which might ameliorate their reproductive behavior risks and result in longer birth intervals and low fertility [59].

A relationship between fertility and mortality can easily be found in our results. Women who had a child-death experience were likely to have a higher number of children than those who had no such experience. As the number of children who died increased, women were exposed to a higher risk of uncontrolled fertility. Casterline suggests that where mortality declines more rapidly, the pace of fertility decline will also be more rapid [60].
Similar results can also be found in many other studies [61-64], which show that child mortality had a significant positive effect on fertility, that is, that an increase in the child mortality rate would significantly increase fertility.

There are some limitations with regard to interpreting the results of this study. Due to the cross sectional design of the study and all the variables analyzed in the regression model, it can only provide evidence of a statistical association between those variables and children ever born and cannot show a cause-effect relationship. The other limitation of the study is, as a measure of fertility, the number of CEB suffers from problems of truncation and censoring as it includes the number of children born up to specific points in women's childbearing years. We should not forget other important errors that could exist in the collection of information regarding the number of children ever born. Women tend to omit some of the children they have given birth to, particularly those living in other households and those who have died, with the result that the proportion children omitted tends to increase with the age of the mother. Another error in the reported number of children ever born arises from the inclusion of stillbirths or late fetal deaths among liveborn children [15]. However, there may in fact be few errors in this regard as it is believed that the Nepal Demographic and Health Survey data were good enough to estimate fertility directly $[1,10]$.

\section{Conclusion}

In Nepal, the number of children ever born is high. Many factors contribute to this phenomenon. Among these factors, age at first marriage, perceived ideal number of children, literacy status, mass media exposure, wealth status, and experience of child death are important and strong predictors that affect fertility. Despite the legal restrictions against marrying at a young age, early marriage is common in the country. Therefore, programs should focus on creating awareness of the marriage law and the disadvantages of early marriage and large family size. 
Table 3: Coefficient of demographic, socioeconomic, and cultural variables on number of children ever born: Multivariate analysis.

\begin{tabular}{|c|c|c|c|c|}
\hline \multirow[t]{2}{*}{ Predictors } & \multicolumn{2}{|c|}{ All women } & \multicolumn{2}{|c|}{ Women aged 40-49 } \\
\hline & Coefficient & t-value & Coefficient & t-value \\
\hline Current Age & 0.502 & $59.5^{* * *}$ & 0.093 & $4.8^{* * *}$ \\
\hline Age at first marriage & -0.152 & $-20.0^{* * *}$ & -0.127 & $-6.5^{* * *}$ \\
\hline Perceived ideal number of children & 0.026 & $3.6^{* * *}$ & 0.038 & $2.0^{*}$ \\
\hline \multicolumn{5}{|l|}{ Place of residence Urban (ref.) } \\
\hline Rural & 0.020 & $2.5^{*}$ & 0.048 & $2.2^{*}$ \\
\hline \multicolumn{5}{|l|}{ Ecological zones Mountain (ref.) } \\
\hline Hill & -0.028 & -1.9 & -0.104 & $-2.7^{* *}$ \\
\hline Terai & -0.027 & -1.8 & -0.095 & $-2.4^{*}$ \\
\hline \multicolumn{5}{|l|}{ Literacy status Illiterate (ref.) } \\
\hline Literate & -0.048 & $-5.4^{* * *}$ & -0.079 & $-3.7^{* * *}$ \\
\hline \multicolumn{5}{|l|}{ Occupation Not working (ref.) } \\
\hline Agricultural sector & 0.009 & 0.9 & 0.015 & 0.52 \\
\hline Non-agricultural sector & -0.015 & -1.6 & -0.001 & -.05 \\
\hline \multicolumn{5}{|l|}{ Religion Hindu (ref.) } \\
\hline Muslim & 0.066 & $8.8^{* * *}$ & 0.146 & $7.6^{* * *}$ \\
\hline Other & 0.001 & $0.13^{* * *}$ & -0.38 & $-1.9^{*}$ \\
\hline \multicolumn{5}{|l|}{ Mass media exposure No exposure (ref.) } \\
\hline One media (either radio or TV) exposure & -0.004 & -0.29 & -0.030 & -1.02 \\
\hline Both (radio and TV) exposure & -0.049 & $-3.68^{* * *}$ & -0.061 & $-1.96^{*}$ \\
\hline \multicolumn{5}{|l|}{ Wealth Status Poor/poorest (ref.) } \\
\hline Middle & -0.070 & $-8.5^{* * *}$ & -0.102 & $-4.83^{* * *}$ \\
\hline Rich/Richest & -0.121 & $-12.3^{* * *}$ & -0.153 & $-6.16^{* * *}$ \\
\hline \multicolumn{5}{|l|}{ Knowledge about FP Lower (ref.) } \\
\hline Higher & -0.001 & -0.13 & 0.017 & 0.80 \\
\hline \multicolumn{5}{|l|}{ Ever used of FP methods Never used (ref.) } \\
\hline Ever used & 0.081 & $10.5^{* * *}$ & 0.107 & $5.29 * * *$ \\
\hline \multicolumn{5}{|l|}{ Household headship Male headed (ref.) } \\
\hline Female headed & -0.016 & $-2.2^{*}$ & -0.038 & $-1.9^{*}$ \\
\hline
\end{tabular}


Table 3: Coefficient of demographic, socioeconomic, and cultural variables on number of children ever born: Multivariate analysis. (Continued)

\begin{tabular}{lcc}
\hline $\begin{array}{l}\text { Experience of child death No (ref.) } \\
\text { Yes }\end{array}$ & 0.311 & $38.9^{* * *}$ \\
\hline $\mathbf{N}$ & 8644 & 2007 \\
\hline $\mathbf{R}$-Square & $0.597^{* * *}$ & $0.325^{* * *}$ \\
\hline Note ${ }^{* *}$ Significant at $\mathrm{P}<0.001 ;{ }^{* *}=\mathrm{p}<0.01$ and $^{*}=\mathrm{p}<0.05$
\end{tabular}

Similarly, more emphasis needs to be place on messages conveyed via the mass media, addressing the advantages of small family size and family planning. Mass media can present a wider range of knowledge and lead to adopting contraception. Furthermore, long-running programs focusing on increasing literacy status and wealth status are essential to improve the reproductive health status of women. Similarly, the relation between fertility and child mortality experienced by mothers was found to be very strong and positive in the study. Programs that focus on reduction of infant and child mortality could also be considered, which would also help to reduce fertility. In short, it can be concluded that programs should aim to reduce fertility by focusing on all these identified predictors so that fertility as well as infant and maternal mortality and morbidity can be decreased and the overall wellbeing of the family maintained and enhanced.

\section{Competing interests}

The author declares that they have no competing interests.

\section{Authors' contributions}

RA, Lecturer at Mahendra Ratna Campus, Kathmandu, conducted data analysis, interpretation, and drafted the manuscript.

\section{Acknowledgements}

The author thanks MEASURE DHS + for providing access to the data.

\section{Author Details}

1 Geography and Population Department, Mahendra Ratna Campus, Tribhuvan University, Kathmandu, Nepal and 2 Institute for Population and Social Research, Mahidol University, Salaya, Thailand

Received: 13 October 2009 Accepted: 28 April 2010

Published: 28 April 2010

\section{References}

1. CBS: Population monograph of Nepal. Central bureau of statistics, Kathmandu: 2003

2. Karki YB: Fertility and the value of children: A study of rural and urban populations in Nepal. In Ph.D. Thesis London school of economics, London; 1982.

3. PRB: Population Reference Bureau, 2009 world population data sheet. Washington DC 2009.

4. Karki YB: Estimates of total fertility rates for Nepal and its geographical sub-divisions and administrative zones 1971 and 1981. National commission on population, Kathmandu, Nepal; 1984

5. Joshi PL, David AS: Demographic targets and their attainments the case of Nepal. National commission on population, Singha Durbar, Kathmandu, Nepal; 1983.
6. National Planning Commission: Seventh plan (1985-90), part I (in Nepali). Kathmandu, Nepal 1986.

7. Ministry of Health $(\mathrm{MOH})$ : Nepal fertility, family planning and health status survey, 1991. Kathmandu, Nepal 1993.

8. Ministry of health [Nepal], New Era, ORC Macro: Nepal demographic and health survey 2001. Calverton, Maryland, USA: Family health division, ministry of health; New Era and ORC Macro; 2002.

9. World Bank: MDG: Reduce by three-quarters, between 1990 and 2015, the maternal mortality ratio. Development Report 2003:208-212.

10. Ministry of health and population (MOHP) [Nepal], New ERA, and Macro International Inc: Nepal demographic and health survey 2006. Kathmandu, Nepal: ministry of health and population, New ERA, and Macro International Inc; 2007.

11. Ezeh AC, Dodoo FN: Institutional change and African fertility transition: the case of Kenya. Genus 2001:135-164.

12. Bongaarts J: Fertility transitions in developing countries: progress or stagnation? Studies in Family Planning 2008, 39:105-110.

13. Garenne M: Situations of fertility stall in sub-Saharan Africa. Paper presented at the 5th African Population. Conference. UAPS, Arusha, Tanzania, 10-14 December 2007

14. Shapiro D, Gebreselassie T: Fertility transition in sub-Saharan Africa: falling and stalling. Afr Popul Stud 2008, 23:3-23.

15. United Nations: Manual X: Indirect techniques for demographic estimation. Population Studies, No. 81. New York 1983.

16. Cochrane SH: Fertility and education. Baltimore: The John Hopkins University Press; 1979.

17. WHO: Health system in Nepal: Challenges and strategic options. Kathmandu 2007.

18. Kamnuansilpa $\mathrm{P}$, Chamratrithirong $\mathrm{A}$ : Contraceptive use and fertility in Thailand: Result from the 1984 contraceptive prevalence survey. Bangkok: Research center national institute of development administration and Institute for population and social research, Mahidol University; 1985

19. Kazi S, Zeba AS: Productive and reproductive choices: Report of a pilot survey of urban working women in Karachi. The Pakistan Development Review 1986, 25(4):594-606.

20. Sibanda A, Woubalem Z, Hogan DP, Lindstrom DP: The proximate determinants of the decline to below-replacement fertility in Addis Ababa, Ethiopia. Studies in Family Planning 2003, 34(1):1-7.

21. Serbessa DD: Differential impact of women's educational level on fertility in Africa: The case of Ethiopia. Addis Ababa 2003.

22. Adioetomo SM: Age at marriage and fertility in Java-Bali, a question of natural or controlled fertility. Majalah Demografi Indones 1983, 10(20):49-72.

23. Mohammad A: Age at first marriage and cumulative fertility in Pakistan. Asian Population Studies Series 1985, 59:40-50.

24. Shah NM, Shah MA, Radovanovic Z: Patterns of desired fertility and contraceptive use in Kuwait. International Family Planning Perspectives 1998, 24(3):133-138

25. Lee BS, Louis GP: The influence of rural-urban migration on migrant's fertility in Korea, Mexico and Cameroon. Population and Development Review 1993, 12:3-26.

26. Mboup G, Tulshi S: Fertility levels, trends, and differentials. In Demographic and Health Surveys Comparative Studies No. 28 Calverton, MD: Macro International; 1998. 
27. Muhuri PK, Ann KB, Shea OR: Socioeconomic differentials in fertility. In Demographic and Health Surveys Comparative Studies No. 13 Calverton, MD: Macro International; 1994

28. Yi Z, James WV: The impact of urbanization and delayed childbearing on population growth and aging in China. Population and Development Review 1989, 15(3):425-445.

29. Sisouphanthong B, Xaovana V, Louangvixa B, Chanthalanouvong T: Lao reproductive health survey. Lao department of statistics. Vientiane 2000

30. Retherford RD, Thapa S: Fertility in Nepal, 1981-2000: Level, trend, and component of change. Population and Health Series, No. 1112003.

31. Zarate AO: Some factor associated with urban-rural fertility differential in Mexico. Population Studies 1967, 21(3):283-293.

32. Balakrishnan TR, Lapierre-Adamcyk E, Krotki KJ: Family and childbearing in Canada: A demographic analysis. Toronto: U of T Press; 1993.

33. Martin TC: Women's education and fertility: Result from 26 demographic and health surveys. Study in Family Planning 1995, 26(4):187-202.

34. Pradhan H: A Study on the determinant of fertility in Nepal. Population and Social Research 1993:48-51.

35. Tawiah EO: Determinants of cumulative fertility in Ghana. Demography 1984, 21(1):1-8

36. Caldwell J: Fertility decline in Africa: A new type of transition? Population and Development Review 1992, 18(2):211-242.

37. Pearce LD: Religion's role in shaping childbearing preferences: The impact of Hinduism and Buddhism. Presented at the population association of America annual meeting, 2001, March 29-31, Washington, DC

38. Mistry M: Role of religion in fertility and family planning among Muslims in India. Indian Journal of Secularism 1995, 3(2):1-33.

39. Adioetomo SM: The role of religion in the construction of the small family norm in Java, Indonesia. Journal of Population 1995, 1(1):107-129.

40. Mullatti L: Religious and ideological orientations and characteristics. Journal of Comparative Family Studies, special issue: Families in Asia: Beliefs and realities 1995, XXVI(1):11-25.

41. Balasubramanjan K: Hindu-Muslim differentials in fertility and population growth in India: role of proximate variables. Artha Vijnana 1984, 26:189-216.

42. IIPS (International Institute for Population Sciences) and ORC Macro: National Family Health Survey (NFHS-2), 1998-99: India. Mumbai: International institute for population sciences; 2000

43. Gulati SC: Contraceptive method's use and choice in Kerala and Uttar Pradesh: Multinomial logit analysis of NFHS data. Demography India 1996, 25(2):205-220

44. IIPS (International Institute for Population Sciences): National Family Health Survey (MCH and Family Planning): India 1992-93. Bombay: International institute for population sciences; 1995.

45. Bhatia PS: Population growth of various communities in India--Myth and reality. Demography India 1990, 19(1):121-129.

46. Flora JA, Maibach EW: Cognitive responses to AIDS information: the effect of issue involvement and message appeal. Communication Research 1990:759-774.

47. Caldwell JC: Theory of fertility decline. London: Academic press; 1982

48. Reed H, Rona B, Casterline J: The role of diffusion processes in fertility change in developing countries: Report of a workshop. Washington, D.C.: National academy press; 1999

49. Saksena DN, Rastogi SR: The reach and effectiveness of media used for popularising the family planning programme. Journal of Family Welfare 1989, 35(3):26-38

50. Easterlin RA: Population and economic change in developing countries. Chicago: University of Chicago Press; 1980.

51. Robinson W: The economic theory of fertility over three decades. Population Studies 1997, 51:63-74.

52. Feyisetan BB, Casterline JB: Fertility preferences and contraceptive change in developing countries. International Family Planning Perspectives 2000, 26(3):100-109.

53. Bongaarts J, Potter RG: Fertility, biology, and behavior: An analysis of the proximate determinants. New York: Academic press; 1983.

54. Bongaarts J: Implications of future fertility trends for contraceptive practice. Population and Development Review 1984, 10(2):341-352

55. Debavalya N: Female employment and fertility. Institute of population studies, Chulalongkorn University; 1977.
56. Castle SE: Intra-household differentials in women's status: household function and focus as determinants of children's illness management and care in Rural Mali. Health Transition Review 1993, 3(2):137-157.

57. Gupta DM: Death clustering mothers' education and the determinants of child mortality in Rural Punjab, India, Population Studies. 1990, 44(3):489-505.

58. Wickrama K, Keith P: Use and evaluation of health care services by male and female-headed households in rural Sri Lanka. The Journal of Developing Areas 1990, 25:1-14.

59. Dyson T, Moore M: On kinship structure, female autonomy, and demographic behavior in India. Population and Development Review 1983, 9(1):35-60

60. Casterline J: Diffusion process and fertility transition. In diffusion processes and fertility transition: selected perspectives. Edited by: Casterline J. Washington, WA: National Academic Press; 2001:1-38.

61. Dust $K$ : The effect of education, income, and Child mortality on fertility in South Africa. University of Victoria; 2003.

62. Randall SC, Legrand TK: Is child mortality important? Reproductive decisions, strategies and outcome in Senegal. Department of anthropology, University College London; 2000.

63. Hossain MB, Phillips JF, LeGrand TK: The impact of childhood mortality on fertility in six rural Thanas of Bangladesh. In Population Council OneDag Hammarskjold Plaza, New York, New York 10017 USA; 2005

64. Alene GD, Worku A: Differentials of fertility in North and South Gondar zones, northwest Ethiopia: A comparative cross-sectional study. BMC Public Health 2008, 8:397.

Pre-publication history

The pre-publication history for this paper can be accessed here: http://www.biomedcentral.com/1471-2393/10/19/prepub

doi: 10.1186/1471-2393-10-19

Cite this article as: Adhikari, Demographic, socio-economic, and cultural factors affecting fertility differentials in Nepal BMC Pregnancy and Childbirth 2010, 10:19

\section{Submit your next manuscript to BioMed Centra and take full advantage of:}

- Convenient online submission

- Thorough peer review

- No space constraints or color figure charges

- Immediate publication on acceptance

- Inclusion in PubMed, CAS, Scopus and Google Scholar

- Research which is freely available for redistribution 